\title{
Face Recognition in Law Enforcement: A Comparative Analysis of China and the United States
}

\author{
Lulu Wang \\ School of Social and Political Science, The University of Edinburgh, Edinburgh, UK \\ Email: 1.wang-122@sms.ed.ac.uk
}

How to cite this paper: Wang, L. L. (2021). Face Recognition in Law Enforcement: A Comparative Analysis of China and the United States. Open Journal of Social Sciences, 9, 498-506. https://doi.org/10.4236/jss.2021.910036

Received: September 28, 2021

Accepted: October 26, 2021

Published: October 29, 2021

\begin{abstract}
The use of facial recognition is becoming increasingly widespread in China, with mobile phones, banks, police stations and so on. Facial recognition has brought a certain benefit to social life in China, but in some areas of the United States facial recognition is prohibited. Facial recognition. This article discusses the use of face recognition in national law enforcement and compares commercial applications with those in China and the United States. Through comparison, we can understand the influence of face recognition in a different environment and the different effects of different application forms. The macro interaction between technology, the state and business shapes the social construction, and at a micro level everyone in society needs to be informed and aware of the costs and risks of using face recognition. Increased individual self-awareness helps to counteract the potential technological cage.
\end{abstract}

\section{Keywords}

Face Recognition, Chins, the United States, Comparison

\section{Introduction}

I noticed that my grandmother's new neighbourhood had installed a face recognition system at the door. The face recognition system is used to access the residential area's access control, which is used to determine whether the person entering the residential area is a resident of the residential area. If so, the door will automatically open, if not, people need to explain to the community security to come here and register personal information before entering. So I randomly asked eight of my grandmother's neighbours if they had any ideas about instal- 
ling a face recognition system at the entrance to the neighbourhood to control access. Their point of view has the following two aspects: 1) convenient, the household direct brush face speed can quickly enter the community. 2) Security, facial recognition in access control applications can control who enters the community, can prevent people who are not residents of the community.

The city that my grandmother lives in belongs to the $4^{\text {th }}$ and $5^{\text {th }}$ line of China. Face recognition can be used to access residential area in the $4^{\text {th }}$ and $5^{\text {th }}$ line of cities, reflecting something and an inevitable trend. Of course, the range of application of face recognition system is extensive; the combination of face recognition and access control is only one of the applications of face recognition. Facial recognition can also be used as account login, timecard, search for missing persons, etc.

So what exactly does facial recognition give us? How do we view the impact of face recognition systems? According to the use of the main body of face recognition, face recognition is used by the state and enterprises, respectively. The state adopts facial recognition as a governance method for law enforcement departments, such as Shoplifting, suspect tracking and investigation (Zhao et al., 2003). Alternatively, enterprises can develop the technology as a commercial product, such as WeChat payment, Amazon Recognition, etc. The public debate over the reaction to facial recognition systems has focused on privacy (Steinacker et al., 2020), public acceptance and discrimination.

This paper discusses the use of face recognition in national law enforcement and compares commercial applications with those in China and the United States.

Why choose China and the US for comparison?

First, through comparison, we can understand the influence of face recognition in a different environment and the different effects of different application forms. Second, both countries lead the world in the number of cameras used. The United States ranks first in the number of cameras per 100 people, while China ranks second ${ }^{1}$. The last, these two countries have different forms of state organisation. China and the United States are one of the One-Party Socialist Republic and the Federal Parliamentary Republic respectively and represent these two different political categories.

\section{Facial Recognition and Law Enforcement}

Facial recognition is a technology that can detect and measure facial features quickly and accurately (Liu, Yan, \& Hu, 2021). Whether in China or the United States, or European countries, law enforcement agencies or governments will use biometric collection to monitor the public. Matching biological information with individuals improves the efficiency of law enforcement departments in searching for individuals, and this efficiency improvement can be applied to searching for suspects, quickly getting information and contact of individuals, to ${ }^{1}$ The websites address of the rank is https://www.precisesecurity.com/articles/Top-10-Countries-by-Number-of-CCTV-Cameras. 
obtain more clues efficiently.

The main features of face recognition can be summarised as identity verification and monitoring (Xing, 2020). With The increasing importance of surveillance-related applications (Zhao et al., 2003), surveillance in face recognition has become more common. There are two main topics between face recognition and law enforcement. One is that face recognition is used by law enforcement. The combination of the two has a corresponding impact on the public all over the world. The second is that the legal integrity of face recognition, both private and public, lags behind the complete adoption and innovation of the technology (Steinacker et al., 2020).

Xiao noted that China's use of the Internet and artificial intelligence technology has increased government surveillance of the public, leading to a shift toward digital centralization./n/nPublic Freedoms are limited by the state's access to big data, and the collection of facial information by law enforcement agencies across the country is part of that monitoring (Xiao, 2019). Some scholars also argue that Chinese citizens do not have the exact self-protection mechanisms as American citizens, namely that the Chinese public cannot have their right to privacy in public places and oppose unreasonable seizure and search (Lopez, 2020). The Chinese government's digital regulatory and other policies to enhance its surveillance of its citizens are the focus of international discussion. Will the public's sense of privacy and freedom diminish under the supervision of the state? Indeed, China has the most considerable acceptance of facial recognition (Kostka, Steinacker, \& Meckel, 2021). Moreover, Chinese responses are more likely to be technology optimists concerned with the convenience technology brings to their lives (Wang \& Zhang, 2019).

The use of facial recognition in China and the United States has protected individuals' privacy for the public response. There has been a "First case of face recognition"2 in China [In October 2019, Guo Bing, an associate professor at the Zhejiang Sci-Tech University in China, filed a lawsuit against the Hangzhou Wildlife World Co., Ltd. over the company's forced face painting. The Fuyang District People's Court in Hangzhou has officially accepted the case; the case became the "First face recognition case" brought by Chinese consumers.], in which a citizen has resisted being forced to input face information. In April 2020, Guo Bing, the plaintiff in China's first facial recognition case, received compensation of 1038 yuan, and Hangzhou Wildlife World Co. Ltd deleted Guo Bing's facial features and fingerprint identification information. San Francisco was the first city in the United States and the world to ban facial recognition. In May 2019, the Board of Supervisors of San Francisco, the US state of California, passed a Stop Secret Surveillance Ordinance. The decision bans the use of facial recognition technology by all government departments in the city, including po-

${ }^{2}$ In October 2019, Guo Bing, an associate professor at the Zhejiang Sci-Tech University in China, filed a lawsuit against the Hangzhou Wildlife World Co., Ltd. over the company's forced face painting. The Fuyang District People's Court in Hangzhou has officially accepted the case; the case became the "First face recognition case" brought by Chinese consumer. 
lice stations.

Citizens in both countries disagree about face recognition, but the social background of the disagreement is different. The relationship between the police and the public and the social environment faced by ethnic minorities are different in China and the United States. Hence, citizens view face recognition differently in terms of discrimination and privacy. Due to the reports of police violence in the United States, the public may feel revolt against the police officers' search for their information through face recognition, and the reduction of discrimination in the social background of diverse nationalities and ethnic groups is the reason for the widespread public resistance to face recognition in the United States (Xing, 2020). China's focus on collective interests, and the public's resistance to face recognition, is more personal than the civil disorder.

So, should states have access to personal information in face recognition?

The American public has resisted face recognition, but the public is more receptive to the use of facial recognition by the central government than private companies, and so is China. The use of facial recognition for surveillance by law enforcement is not a matter of public concern but rather the convenience and increased security of face recognition applications (Kostka, Steinacker, \& Meckel, 2021). Biometric features in face recognition are not lost, transmitted, or stolen. The use of biometric features requires a real user to access specific resources, which improves security (Zhang \& Kang, 2019).

The strengthening of state social monitoring can predict people's movements and can quickly deal with social emergencies. For example, the new crown pneumonia epidemic, for China, in a short time, the greatest efforts to mobilise national resources, the use of digital organisation, the use of QR codes, face recognition to match personal information quickly, in order to organise the public's work, isolation, treatment and other issues. Moreover, the combination of face recognition and infrared temperature measurement technology can realize "Non-contact temperature measurement", which is widely used in epidemic prevention and control. Coupled with a shift in power from the highest levels of the national government to grassroots collaboration, China quickly took the lead in the spread of the epidemic.

In addition to the national grasp of personal biological characteristics for public security, private enterprises' collection of face information can play a more commercial value. The intervention of state forces can organise the collection of face information and the wide range of applications with the highest efficiency. Compared with private enterprises, it also has a more potent authority.

Whether it is the United States or China, facial recognition is to a certain extent the lack of explicit use standards. Continuing improvements in facial recognition applications in China, the United States and other countries include establishing and improving safety and accountability thresholds for face recognition technology use, distinguishing between public and private sector spaces for face recognition and different focuses for public and private use. Simultaneously, 
the collection of face information is more powerful than the collection of general personal information. The improvement of the system can also improve the security of technology application and the protection of public rights.

\section{Face Recognition and Commercial Applications}

The widespread use of face recognition includes the demands of government departments for public safety, commercial organisations for efficiency and cost reduction, and artificial intelligence technology companies for business growth. Some reporters pointed out that after the big companies open-source some algorithms, the threshold of face recognition technology has been dramatically reduced. Many companies with modest technological capabilities have acquired the ability to use face recognition. Still, the collection and storage of facial data can not guarantee a certain degree of security. These companies often collect and store basic facial information directly, ignoring security concerns.

At the beginning of the article, I mentioned that my grandmother's neighbourhood had a facial recognition system for entry. How to store and use the face photos of residents after collection and whether there will be information security problems deserve our attention. The neighbourhood developers and the property owners how to keep the collected personal information confidential and manage also need clear instructions. In addition to the need to maintain public safety, face recognition technology often makes face data obtained by organisations or systems without any qualifications or even forced to use. As a result, the criminal problems exposed by the misuse of face data are likely to outweigh the need for public safety.

The relationship between business companies and the government is also different in China and the United States. There are different criteria between business companies and the government on whether facial recognition should be used. Public Safety Protection seems to be a criterion to consider when using face recognition.

The databases in the United States are not interconnected, and government enforcement will require data from large companies in partnership with many technology companies. For example, in June 2020, Amazon banned police from using its widely used facial recognition software, rekognition, and Microsoft, until the country perfected its legal system. In contrast to China, the information obtained by the service providers belongs to China. In addition to commercial use, the content of the service providers platforms also needs to be managed by the state, and the international export of data also needs to be agreed upon and managed by the state (Xiao, 2019).

In China, the state holds the majority of the biometric information gained through face recognition. The facial recognition technology of the service providers comes from the popularity of technology companies and national technology rather than the uniqueness of the technology. Service providers in the United States have the advantage of patenting their technology and self-control 
of their technology and database, forming a mode of dialogue with the government and restricting the use of the US government to some extent. So, China can carry out international protection of data from the national level, limiting the information leakage caused by data sharing of international cooperation between commercial companies to some extent. However, to a certain extent, it will also restrict the autonomy of enterprises. The power of the United States has been decentralised under mutual constraints, which can better provide the social subjects of the pursuit of rights channels and maximise the strength of different subjects.

It seems that, under the influence of face recognition, different relationships between different countries and commercial companies are diverging in the world. Moreover, commercial companies' possible disclosure of personal privacy is also a common problem faced by China and the United States. Therefore, the regulations on facial recognition of commercial products need further standardise the use range and standards of face recognition.

In addition, different countries and commercial companies in the face recognition and other artificial intelligence technology, the impact of social structure, we also need to think about how. The long-term leadership of the state over facial recognition and its data in commercial companies, and the partnership between the state and commercial companies in facial recognition projects, will bring about changes in society over the long term and a power shift. The application of face recognition in different countries also reflects the interaction between technology, government and enterprise.

\section{The Cultivation of Rational Individuals}

After the text edit has been completed, the paper is ready for the template. Duplicate the template file by using the Save As command, and use the naming convention prescribed by your journal for the name of your paper. In this newly created file, highlight all of the contents and import your prepared text file. You are now ready to style your paper.

The combination of artificial intelligence, such as face recognition, law enforcement and supervision, can be seen as a way to reshape the government's power. But whether in the United States or China, the public is responding in different ways to questions about the privacy and freedom of facial recognition. For example, San Francisco in the United States first banned the use of face recognition. China has also emerged "Face recognition of the first case," a legal way to oppose the admission of visitors to the scenic zoo spot mandatory facial information.

Intense state supervision or law enforcement cannot prevent conflict between the law enforcement departments and the privacy issues involved in face recognition. Both China and the United States are making efforts to perfect the legal system of face recognition. With the improvement of education, the deepening of global rational thinking, and the strengthening of individual self-consciousness, 
the public's consciousness is also promoting the policy change and response of the state power organisation.

We should pay attention to the range of use of facial recognition, legal norms and the differences between countries. We should also be aware that artificial intelligence such as face recognition is reshaping the way society regulates and the scope of individual privacy. Furthermore, as a means of technological change, artificial intelligence has brought about changes in lifestyle and changes in the economy, productivity, and social structure (Li, 2020).

The intelligence degree of human society is constantly deepening, and the technical foundation of artificial intelligence embedded in our society is also constantly being consolidated. Increased security from technology also seems to increase public acceptance of technologies such as face recognition (Kostka, Steinacker, \& Meckel, 2021). The improvement of the degree of acceptance, the convenience of technology, the ease of bringing people to the pursuit of technology and optimistic use, and ignoring its hidden dangers. The Center for Science and technology research at Tsinghua University points out that people's attitudes toward artificial intelligence are becoming more rational. People have gone from fanaticism to reflection on the potential pitfalls of artificial intelligence.

According to this article, the improvement of digital social regulation in China does not represent the road to digital centralisation, nor can it be regarded as unique to China. In addition to the problems that facial recognition technology brings in different fields. It is more important to judge whether a series of changes are brought about by the new technology form or the transformation of the existing problems in society, or the amplification and presentation of prejudice. The Chinese government uses technologies such as face recognition for social supervision, showing that the power is in the hands of the government and human beings. On the other hand, when the US government uses technologies such as face recognition for social governance, technology is more instrumental. We now belong to the artificial intelligence aided human dictatorship (Zhe, 2018). People are faced with how to play the technological advantages, maintain human independence, and the technical risk pre-investigation and solution.

Researchers in the digital age need to think about how to face and defuse technological risks so that artificial intelligence can genuinely become good technology, which requires both development and governance and promotion and limitation (Li, 2020). China and the United States use face recognition in different ways. The operation mode of social supervision can be used for reference by each other. However, the political, social and technical reasons behind the face recognition information need to be explored and analysed; it makes the world more rational to use face recognition.

But when the use of technology beyond human control, the power of technology will be greater than human control, that is, artificial intelligence free from human supervision, into the stage of autonomous evolution (Wang, 2001), coping with technological autonomy is a global topic. So individual conscious- 
ness should be in line with the topic of the times. The enhancement of individual rational thinking can promote different countries and the world to understand technology and the promotion society more perfect system and a series of social topic development.

In the use of face recognition, many scholars study the public acceptance and investigate the factors that influence the public perception of face recognition. The education level is not always significant. The correlation between public education and acceptance is still worth exploring. The increase in individual education plays a vital role in an individual's judgment of his or her environment and understanding of the risks. The general audience should be aware of the cost and risk in the process of using face recognition. When the individual's rational consciousness is improved, it can complement the national supervision, and the individual has an independent judgment for the national supervision. The role of state supervision is not only to predict the behaviour of citizens but also to protect the collective of people with different levels of education.

\section{Conclusion}

In the application of face recognition in China and the United States, there are public responses based on the protection of individual privacy. Citizens of the two countries have different opinions on face recognition. However, the social background is diverse, so the citizens emphasise the discrimination and privacy of face recognition. While analysing the problems that face recognition technology may bring, it is more important to judge whether a series of changes result from new technological forms or the amplification and transformation of preconceptions that already exist in society.

China and the United States have different relationships with commercial facial recognition programs. China has long been a leader in face recognition and its data. The United States has a partnership with commercial facial recognition programs. The application of face recognition in different countries also reflects the interaction between technology, government and enterprise.

The macro interactions between technology, state and business shape the structure of society, and each individual in society at the micro-level needs to understand and be aware of the costs and risks involved in using face recognition. An increase in personal self-awareness helps to counter the potential technological cage.

\section{Conflicts of Interest}

The author declares no conflicts of interest regarding the publication of this paper.

\section{References}

He, Z. (2018). Will Artificial Intelligence Form a New Autocracy?: History and Future of Human Politics. Journal of Party School of CPC Tianjin Municipal Committee, 6, 3-10. 
Kostka, G., Steinacker, L., \& Meckel, M. (2021). Between Security and Convenience: Facial Recognition Technology in the Eyes of Citizens in China, Germany, the United Kingdom, and the United States. Public Understanding of Science (Bristol, England), 30, 671-690. https://doi.org/10.1177/09636625211001555

Li, H. (2020). Sociological Considerations Caused by the Fusion of Digital Humanism and Artificial Intelligence. Internet World, 11, 18-23.

Liu, Y., Yan, W., \& Hu, B. (2021). Resistance to Facial Recognition Payment in China: The Influence of Privacy-Related Factors. Telecommunications Policy, 45. https://doi.org/10.1016/j.telpol.2021.102155

Lopez, A. E. (2020). The Use of Facial Recognition Technology by the United States and China, and How It Affects Civil Liberties. ProQuest Dissertations Publishing.

Steinacker, L., Meckel, M., Kostka, G., \& Borth, D. (2020). Facial Recognition: A Cross-National Survey on Public Acceptance, Privacy, and Discrimination.

Wang, D. L. (2001). Unsupervised Learning: Foundations of Neural Computation: A Review. The AI Magazine, 22, 101.

Wang, Z., \& Zhang, L. (2019). Security, Privacy and Civil Liberties: Reflections on the Technical Security of Facial Recognition Systems in Public Places. Journal of Party School of Shengli Oilfield, 32, 74-76.

https://doi.org/10.13600/j.cnki.jpsslof.issn.1009-4326.2019.01.016

Xiao, Q. (2019). The Road to Digital Unfreedom: President Xi's Surveillance State. Journal of Democracy, 30, 53-67. https://doi.org/10.1353/jod.2019.0004

Xing, H. Q. (2020). Legal Regulation of Face Recognition. Comparative Study Method, 5, 51-63.

Zhang, W. K., \& Kang, M. J. (2019). Factors Affecting the Use of Facial-Recognition Payment: An Example of Chinese Consumers. IEEE Access, 7, 154360-154374. https://doi.org/10.1109/ACCESS.2019.2927705

Zhao, W., Chellappa, R., Phillips, P., \& Rosenfeld, A. (2003). Face Recognition: A Literature Survey. ACM Computing Surveys, 35, 399-458.

https://doi.org/10.1145/954339.954342 